\title{
Analysis of Internal and External Factors Affecting the Development of Cross-Strait Cultural and Creative Industries
}

\author{
Xing $\mathrm{Li}^{1, \mathrm{a}}$, Zihan Yang ${ }^{1, \mathrm{~b}}$ and Bingjie $\mathrm{Hou}^{1, \mathrm{c}}$ \\ ${ }^{1}$ College of Economy and Management, LongDong University ,QingYang, City, Gansu \\ aleebj@189.cn, b455248638@qq.com, ${ }^{\mathrm{c} 852738044 @ q q . c o m}$
}

Keywords: Cross-strait creative industries; Factors for development; Industrial economy

\begin{abstract}
By selecting iconic cities from Chinese mainland and Taiwan, this paper introduced the present situation of cross-strait cultural and creative industries, detailing the overall development of the creative industries. Based on creative industry development factor theory, this paper analyzed internal factors affecting the development of creative industries, including enterprise interaction, regional networking, innovation system, and cultural environment, as well as external factors, including facility conditions and government environment. Taipei Cultural \& Creative Zone and Hangzhou Cultural \& Creative Zone were selected for a questionnaire survey, and with the use of principal component analysis, Chinese mainland and Taiwan were compared as to factors affecting the cultural and creative industries and priorities in development, giving some reference for the future study of cross-strait cultural and creative industries. To accelerate the development of creative industries, both sides should in view of these internal and external factors define industrial orientation, promote creative and cultural industrialization, develop creative industry clusters, build creative industry service systems, and strengthen intellectual property management, so as to optimize the industrial environment, enhance the core competitiveness of creative industries, thus to achieve economic and social benefits of the creative industries.
\end{abstract}

\section{Introduction}

With growing trend of globalization and increasingly fierce international competition, cultural and creative industries are no longer a concept of development, but industries with a direct practical significance, containing huge economic benefits. Creative economy creates an output value of 22 billion US dollars per day and grows at a rate of 5\% annually. Its growth rate is faster in some countries, such as the United States with $14 \%$ and the UK with $12 \%$. The scale and degree of development of creative industries has become an important measure of a country or region's level of overall competitiveness. In recent years, creative industries have become strategic industries and pillar industries in many countries and regions who are taking appropriate policy measures and instruments to actively promote their development. For example, Japan proposed the "Intellectual Property National Strategy"; the United States issued a declaration that "capitalist era has passed, the time of creative ideas has come"; Singapore in 2002 published the "Creative Industries Development Strategy"; and so on.

Cultural and creative industries in China have been on the rise and developing for only a few years, but showing a booming trend. In recent years, China has become the third largest exporter of innovative products and services. According to UNCTAD statistics, in 2004 China's creative product exports reached 10.6 billion yuan. Taiwan in 1995 proposed the idea of "cultural industrialization and industrial culturalization", but not until 2002 did it officially list cultural and creative industries as a direction of policy development and also set up a "cultural and creative industries promoting team." In addition, according to statistics of "2008 Taiwan Cultural and Creative Development Report", in 2002 the output value of Taiwan's cultural and creative industries was NT \$ 435.3 billion, by 2007 grew to NT \$ 632.9 billion (accounting for $2.65 \%$ of GDP), i.e. the average annual growth of 7.7 percent, much higher than the average growth rate of 3.7 percent of Taiwan's overall economy, showing the development potential of cultural and creative industries in Taiwan. With the increasingly close cross-strait exchanges, cooperation and competition in cultural 
and creative industries has become a cross-strait common topic. Whether it is Chinese mainland or Taiwan, with the arrival of the era of the creative economy and the rapid rise of creative class in cities, creative orientation is becoming one of the important features of modern urban development. It can be said that creative economy is the soul of modern cities, hailed as the golden industry in future cities, and also a strategic element for a city to form its own core competitive advantage at a higher level. Today, with increasingly fierce international competition and strengthening trends of globalization, the level of development of cultural and creative industries with culture and creativity as the core has become an important measure of a city's comprehensive competitiveness.

\section{Research Methods}

Through literature review, existing literature were sorted and compared horizontally and vertically in terms of research direction, methods and results, and necessary presentation, description and evaluation was also done on the contents of literature. In the empirical part, a principal component analysis was done to make a quantitative evaluation of the factors for development of creative industries in the sample areas.

Internal and external factors affecting cultural and creative industries were listed and divided. Internal factors include business interaction, regional networking, innovation system, and cultural environment. External factors include facility conditions and government environment. Among them, business interaction can be divided into specialization and division of labor, competition, cooperation, complementarity and trust and sanctions; regional networking into universities, research institutions and professional training institutions, industry associations and intermediary organizations, flexible labor markets and creative talent; innovation system into innovative approach, collective learning ability, and knowledge spillovers; cultural environment into an open and tolerant environment, cultural resources, and cluster brands; facility conditions into hardware facilities and public information platforms; government environment into planning and guidance, policy support, and environmental management. Specific research framework is as follows:

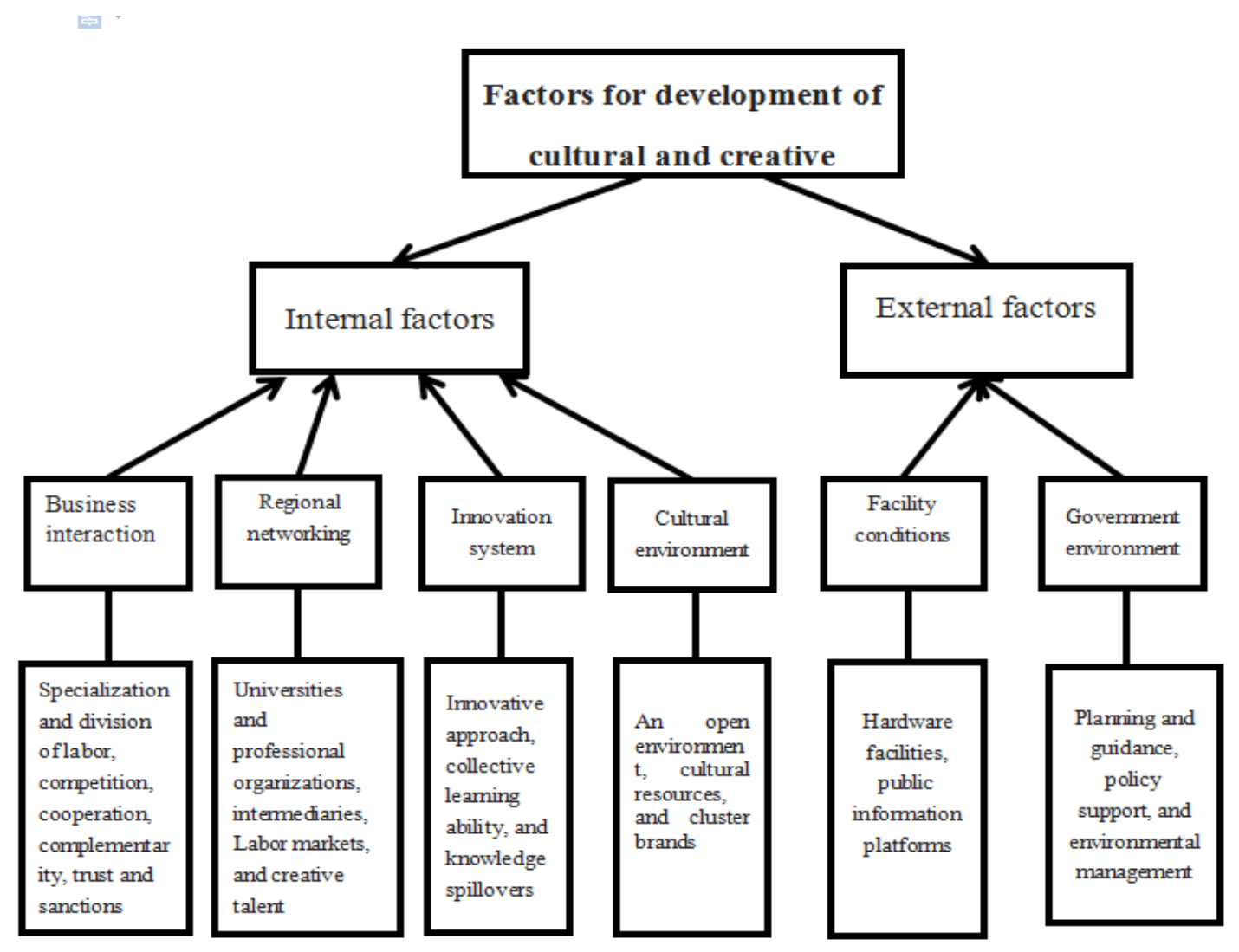

Combined with the previously discussed factors affecting the development of creative industries 
and the research model, this research selected Hangzhou and Taipei as comparative samples and quantitatively evaluated their respective factors affecting the development of creative industries. From an empirical study of cultural and creative gathering areas in Taipei and Hangzhou, this paper identified factors as driving force for development and made a comparison between the two cities to see their respective shortcomings in the development process, which implies great significance for the development path of cultural and creative industries from gathering to clustering in the case of continuous cross-strait cultural exchanges. Objects of this empirical study are enterprises stationed in Hangzhou Xixi Cultural and Creative Park, West Lake Digital Entertainment Industry Park, Taipei Songshan Creative Park, and Huashan Creative Park. Data was collected using questionnaires and later was processed. The objectives and main contents of this empirical study are exploration of internal and external factors for development and comparison of two cities in terms of development focus.

\section{Conclusions \& Results}

Currently mainland China's economic structure is inclined to industry and other traditional industries, while the development of service sector is lagging behind and the regional economic structural conditions necessary to creative industries have yet to be optimized. Taiwan, on the contrary, sees its service industry develop rapidly and has a different regional economic structure from mainland China.

Gathering areas in Chinese mainland are too dependent on external organizational dynamics, while lacking self-organizing power. This shows that enterprises in Chinese mainland think that policy support is a basic condition of cluster development, Enterprises have over-reliance on government, lacking self-organizing power, while relevant guidance of the government is not in place. However, Taiwan has more adequate self-organizing power and brings the basic role of market allocation of resources into full play.

Chinese mainland's cultural and creative industries lack a complete division of labor system, resulting in a low degree of industrial relevance and out-of-line industrial chains, where the role of "division of labor and specialization" is underplayed and the division of labor system between enterprises in gathering areas is not complete. This is mainly reflected in that some areas are still in the initial stage of industrialization and have not yet formed a complete industrial chain, such as design and animation; that some enterprises in gathering areas have an incomplete value networking system with upstream and downstream enterprises and few have long-term and stable cooperative relations; and that the majority of enterprises in gathering areas are operating with a low degree of specialization. The situation in Taiwan is different, where design and animation industries enjoy a sound development; there is a higher degree of specialization in gathering areas and a more complete value networking system between upstream and downstream enterprises.

Chinese mainland and Taiwan are both still lacking innovative elements, where industrial development tends to converge and be manufacturing-based. For example, some manufacturing industries with certain innovative elements are being developed as creative industries; creative parks are being built in the way of transplanting manufacturing industry concept. Due to the absence of core patented technology, this is bound to solidify their low-end position in the chain of creative industries, resulting in the loss of essential connotation of cultural and creative industries.

The role of cross-strait cultural resources is underplayed. In essence, cultural and creative industries have a strong dependence on cultural resources. Due to resource heterogeneity, Hangzhou and Taipei both have the advantage of developing cultural and creative industries, but from the source, the development of cultural and creative industries comes from human creativity and technological, economic and cultural blend, as well as modern business operations, rather than abundant cultural resources. From the perspective of current development situation, the role of culture in both places is significantly underplayed and no cluster brands have been well built.

Lack of a sound competitive environment and a sound market protection mechanism impedes innovation, while resulting in an unfair competitive environment, serious duplicate competition, lack of competitive benchmarking, lack of outstanding model enterprises in gathering areas, and 
insufficient information supply.

\section{Discussion}

The future trends of cultural and creative industries should be the following: First, proceed with education, pay attention to and strengthen the cultivation of innovative talents. Cultural and creative industries as emerging industries require injection of a lot of fresh blood. The key to cultural and creative industries is creativity, while creativity comes from high-quality, complex talents. Second, establish cultural and creative industry demonstration sites and enhance the core competitiveness of cross-strait cultural and creative industries. On established industry bases, it is necessary to find gaps in the market, make full use of existing resources to constantly develop new demonstration sites, so as with parts driving the whole to build the brand value of cultural and creative industries and promote the rapid development and overall competitiveness of cultural and creative industries. Third, the government should strengthen macro-control, moderately guide cultural and creative industries in cluster and business operations, and improve the management mechanism. Strengthen regulation and control, combine with the market, and effectively guide the development of enterprises, so that government, market and enterprises are well coordinated and achieve harmony between. At the same time, establish a sound cultural management mechanism and give full play to cultural management functions of the government. Fourth, Chinese mainland and Taiwan should establish cross-strait local creative industry associations, organize seminars and exhibitions, publish industry information, promote exchanges and cooperation within the industries, give play to the overall advantage to participate in government policy formulation and inter-industry strategic consultations, so as to expand the space of development of creative industries.

\section{Acknowledgement}

Longdong University doctoral research start-up funding project (No.: XYBE1605)

\section{References}

[1] Castells (2000). End of Millennium. Oxford: Blackwell.

[2] Carbone, L. P., (2004), Clued in: How to keep customers coming back again and again. Upper Saddle River, NJ: Finance Times Prentice Hall.

[3] Chacke, G.K. (1988), "Technology Management-Application to Corporate Markets and Military Missions", Praeger, NewYork.

[4] Charles L. (2000) .The Creative City: A Toolkit for Urban Innovators. London: Earthscan.

[5] Connor, S. (1992). Theory and cultural value. Oxford: Blackwell.

[6] David, T. (2001), Economics and Culture. Cambridge, UK: Cambridge University Press.

[7] Den,H. (1999). Conceptualising Service Innovation and Service Innovation Patterns,

[8] Florida, R. (2003) Cities and creative class, City and Community, 2 (3): 3-19.

[9] Lacan, J. (1977). The Mirror Stage as Formative of the Function of the I as Revealed in Psychoanalytic Experience. Ecrits: A Selection. New York: Norton.

[10]Landry, C. (2000). The Creative City: A Toolkit for Urban Innovators,London:Comedia.

[11]Lovelock, C.H. (1983), “Classifying Services to Gain Strategic Marketing Insights,// Journal of Marketing, 47 (3): 9-20.

[12]Lovelock, C.H.(1991).Service Marketing, USA: Prentice-Hall. 
[13]Markusen, A. ,King, D. (2003) The Artistic Dividend: the Arts' Hidden Contributions to Regional Development, Minneapolis: University of Minnesota.

[14]Marquis, D. G. (1972), The anatomy of successful innovation, Managing Advancing Technology, 1, 35-48.

[15]Murdick, R. G., Render B., Russel R. S.(1990). Service Operations Management, Allyn and Bacon Inc., pp.4.

[16]Newell,S. (1995), Professional Associations as Important Mediators of The

[17]Paton, R. A.,McLaughlin, S.(2008). Service Innovation: Knowledge transfer and the supply chain. European Management Journal 26, 77-83.

[18]Philip,K. (2003). Marketing Management. Prentice Hall Pearson Education International: New Jersey. Eleventh Edition, p.134.

[19] Rogers, E. M. (1983). Diffusion of Innovations. (3rd ed). New York: Free Press. C(N). 